“@ 2018 IEEE. Personal use of this material is permitted. Permission from IEEE must be obtained for all other uses, in any current or future media, including reprinting/republishing this material for advertising or promotional purposes, creating new collective works, for resale or redistribution to servers or lists, or reuse of any copyrighted component of this work in other works." 


\title{
A Bidirectional Two-Switch Flyback Converter with Cross-Coupled LCD Snubbers for Minimizing Circulating Current
}

\author{
Nurhakimah Mohd Mukhtar, Student Member, IEEE, and Dylan Dah Chuan Lu, Senior Member, IEEE
}

\begin{abstract}
This paper proposed a novel isolated bidirectional two-switch flyback converter with two integrated non-dissipative inductor-capacitor-diode (LCD) snubbers. In the proposed topology, the main flyback transformer and the LCD snubbers are cross-coupled (CC) to minimize circulating current that would happen in the non-crosscoupled (NCC) case, in addition to recycle leakage energy and protect the power transistors. The same current circulation issue also happens to bidirectional flyback converter with conventional resistor-capacitor-diode (RCD) snubbers. The main objective of this paper is to illustrate this issue and propose an alternate circuitry to reduce the current circulation and improve the conversion efficiency. The experimental results of a laboratory prototype are reported to verify the design.
\end{abstract}

Index Terms-bidirectional; coupled inductor; high voltage gains; isolated DC-DC converter; non-dissipative snubber.

\section{INTRODUCTION}

$\mathbf{N}$ OWADAYS, the demands for clean and sustainable energy sources such as photovoltaic (PV), wind energy and fuel cells have increased rapidly. However, these energies have issues generally with electric power systems in terms of stability, availability and power quality. The energy storage system (ESS) has been serving an important role to overcome some of these drawbacks. The development of green energies is moving towards with integrating the ESS. Thus, bidirectional DC-DC converters (BDCs) are used to interface the ESS with the DC bus for effective power flow control, efficient power conversion and power conditioning [1]-[4]. Bidirectional converters have

N. M. Mukhtar is with the School of Electrical Systems Engineering, Universiti Malaysia Perlis, Arau 02600, Malaysia, and also with the School of Electrical and Information Engineering. The University of Sydney, Sydney, Darlington, N.S.W. 2006, Australia (e-mail: nurhakimah.mohdmukhtar@sydney.edu.au).

D. D.-C. Lu is with the School of Electrical and Data Engineering, University of Technology Sydney, Sydney, N.S.W. 2007, Australia, and also with the School of Electrical and Information Engineering, The University of Sydney, Darlington, N.S.W. 2006, Australia (e-mail: dylan.lu@uts.edu.au).

Copyright @2018 IEEE. Published in the IEEE Transactions on Industrial Electronics, Vol. 66, No. 8, pp. 5948-5957, August 2019. Available: [Online] https://doi.org/10.1109/TIE.2018.2873097. Personal use of this material are permitted. However, permission to reprint/republish this material for advertising or promotional purposes or for creating new collective works for resale or redistribution to servers or lists, or to reuse any copyrighted component of this work in other works, must be obtained from the IEEE. been used in uninterruptible power supplies (UPS) [5]-[8], battery chargers [8]-[12] and electric vehicles (EV) [13][18]. For renewable energy sources, their terminal voltages are usually low and of time-varying nature. The high conversion ratio of DC-DC converters are needed to interface with high DC voltage and provide continuous power supply. The paper presented in [19] explains the controller design and demonstrates the implementation of battery storage as a back-up for both islanded and grid-connected operations.

Bidirectional converter can be classified into three types which are the non-isolated, partially-isolated and isolated converters. The non-isolated bidirectional converters are derived from basic converters such as buck, boost, buck-boost and single ended primary inductor (SEPIC) converters [6], [13], [20]-[22]. The most popular topology such as buck-boost converter offers circuit simplicity and cost-effective structure. However, it has difficulty in attaining high conversion ratio even with extreme duty cycle, due to the presence of parasitic resistance. On the other hand, multilevel converter can be used to achieve high voltage ratio [23]. However, these topologies in general have higher switching losses and complexity because of the large number of power switches. The partially-isolated converter is formed by combining the basic DC-DC converter and coupled-inductor [24]. This topology can achieve high voltage gain at the expense of high voltage stress on switching devices and lacking overall galvanic isolation.

The isolated converters such as flyback converters, forwardflyback converters, half-bridge converters and full-bridge converters have been widely adopted for different power levels [3], [11], [19], [25]-[28]. A popular topology for low power application is the flyback converter due to its circuit simplicity, lower component count and cost, and has isolation between sources and loads [1]-[3], [5], [23], [25]. However, the flyback converter has large leakage inductance issue that causes a high voltage spike when the switch is turned off. This large spike degrades its overall performances of this topology especially in efficiency [4], [29], [30].

An isolated flyback DC-DC converter has been introduced in [31] which has a non-dissipative snubber to decrease the voltage spike during transistor's turn-off instant. A dual voltage-doubler circuit on the secondary side is used to produce a high voltage output. However, this topology is only suitable for unidirectional operation. In [32] the authors proposed a zero-current-switching (ZCS) bidirectional flyback DC-DC converter. It is an extended topology that previously 


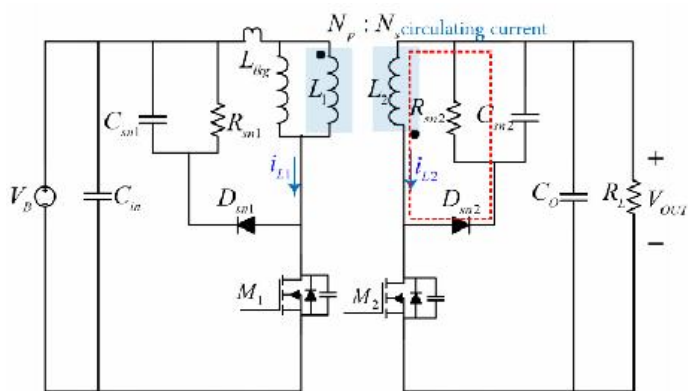

(a) Flyback converter using RCD snubber circuits

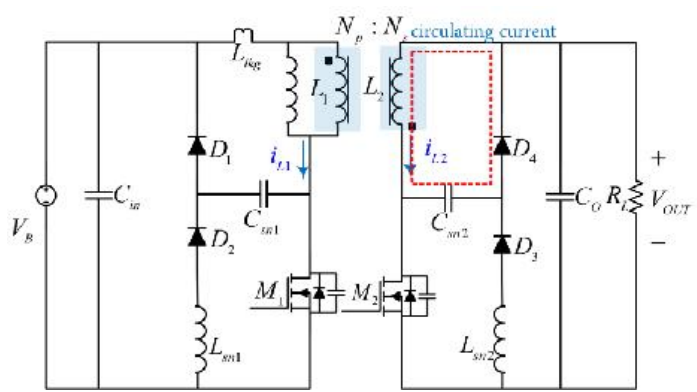

(b) Flyback converter using non-cross-coupled LCD snubber circuits.

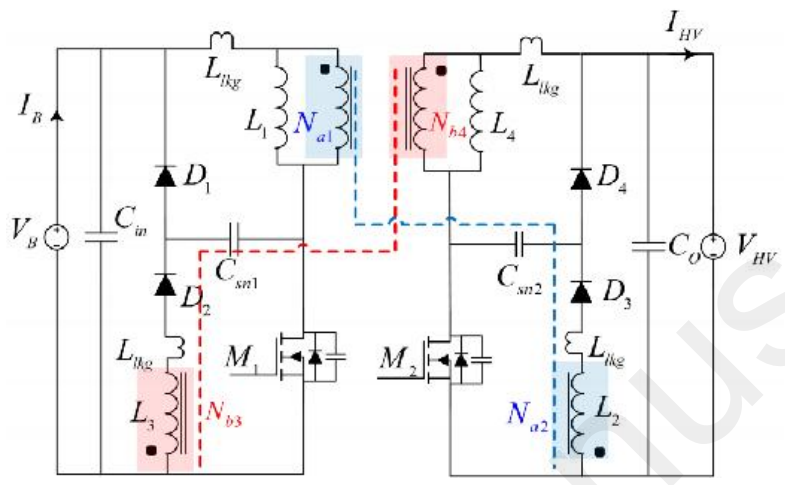

(c) Flyback converter using the proposed cross-coupled LCD snubber circuits.

Fig. 1: Isolated bidirectional flyback converter.

presented in [25], where the authors replaced diode with the power switch to perform bidirectional power flow. In addition, the coupled inductor was implemented in the secondary circuit. However, to achieve the ZCS condition, the number of active switches has increased, and it still suffers from high conduction losses. Tsorng-Juu et al. [33] introduced a bidirectional isolated DC-DC converter with a current-doubler to reduce current ripple. By using synchronous rectifiers, zero-voltageswitching (ZVS) can be achieved on the low voltage side. Nevertheless, this topology requires four power switches. In [34], an isolated bidirectional interleaved converter is derived from the flyback converter with dual-LCD snubbers attached to the primary side for energy recycling purposes. However, this topology requires additional components in the secondary side with quasi-series circuit to achieve boost mode operation. The use of four switches to achieve high efficiency however increases the overall cost.

To reduce the number of active switches as compared to [32]-[34] and provide bidirectional power flow and galvanic isolation, this paper presents a two-switch flyback converter with cross-coupled LCD snubbers. Fig. 1(c) shows the schematic of the proposed converter integrated with two nondissipative LCD snubbers which are denoted as $N_{a}$ and $N_{b}$ for the primary and secondary transformer sides, respectively. $V_{B}$ and $V_{H V}$ represent the battery voltage and higher terminal voltage on the other side respectively; $M_{1}$ and $M_{2}$ are the power switches; $D_{1}-D_{4}$ are the snubber diodes and $C_{s n 1}$ and $C_{s n 2}$ are the snubber capacitors.
Some preliminary results of this topology have been presented in [35]. This paper further evaluates the effectiveness of the converter through more in-depth analysis and comparison with existing topologies. Specifically, a detailed examination on the current circulation problems with non-cross-coupled snubbers and with RCD snubbers, which have not been presented in [35], are now included in this paper in Section II. The operating principles of proposed converter for both in continuous conduction mode (CCM) and discontinuous conduction mode (DCM) modes are explained in the Section III. Section IV discusses the steady state analysis of the step-up modes of operation. Section V discusses the design procedure of the snubber circuits. Section VI reports the experimental verification results of the proposed converter and Section VII concludes the paper.

\section{Current Circulation Problem With RCD AND NON-CROSS-COUPLED LCD SNUBBERS}

In this section, an investigation is carried out on two common approaches to adding snubber circuits for isolated converters (flyback converter is selected in this paper) and to illustrate the associated circulating current problem.

For cost-sensitive applications, the dissipative snubber has been adopted widely due to its circuit simplicity and effectiveness in suppressing the voltage spike. Fig. 1(a) shows the schematic of the flyback converter with an RCD snubber on each side of the transformer. Fig. 2(a) to (c) show the equivalent circuits of the converter during one switching cycle. 


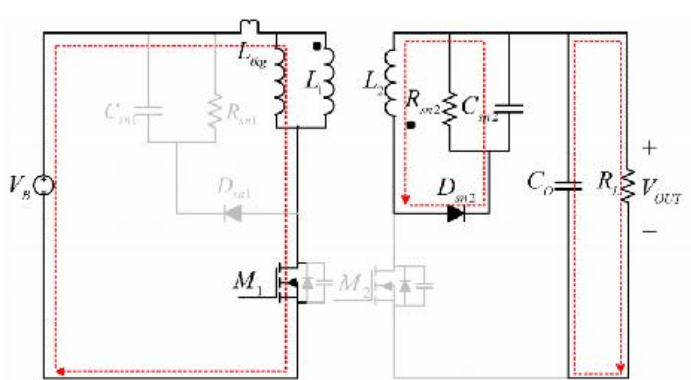

(a)

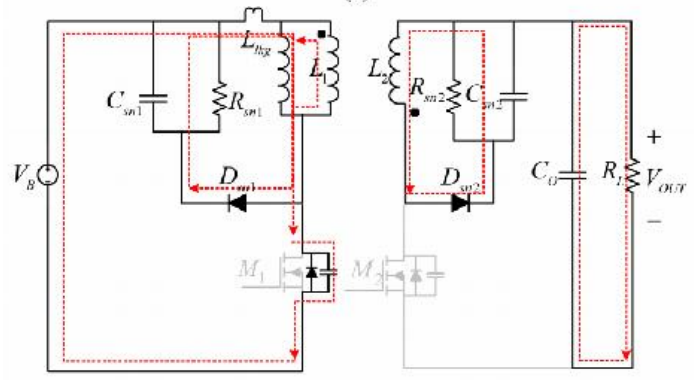

(b)

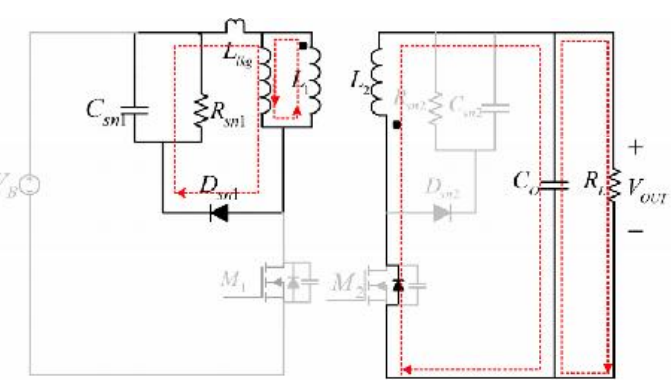

(c)

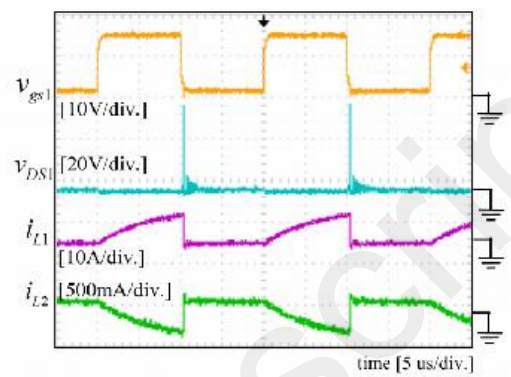

(d)

Fig. 2: Equivalent circuits of the flyback converter (a) - (c) using RCD snubber circuits during one switching cycle in CCM operation. The key waveforms (d) of flyback converter using RCD snubber circuits.

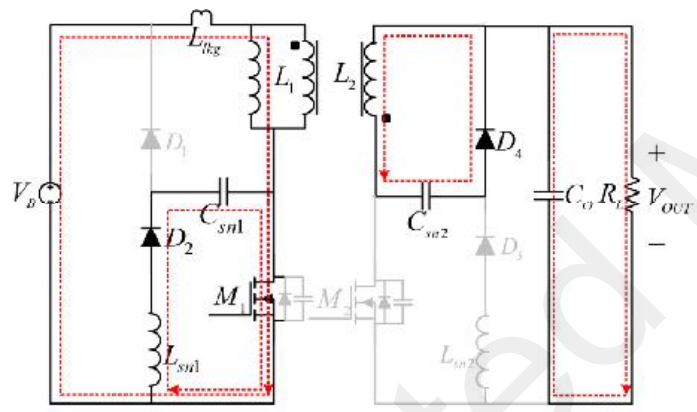

(a)

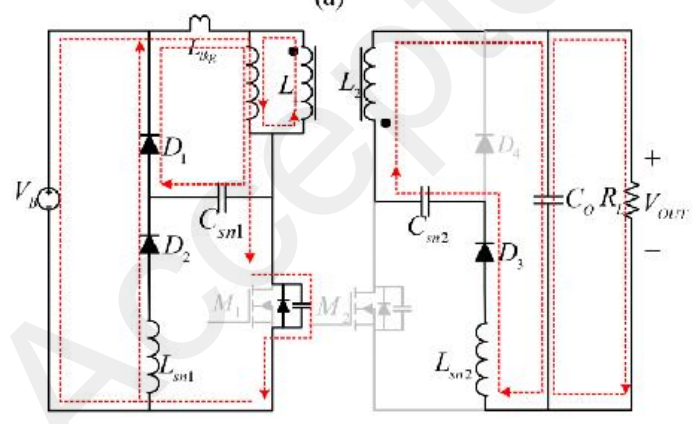

(b)

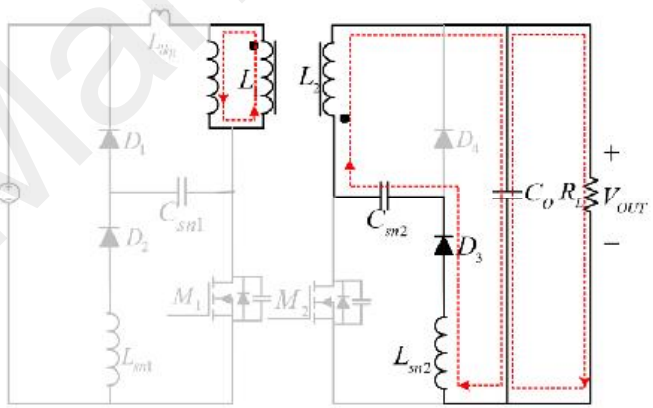

(c)

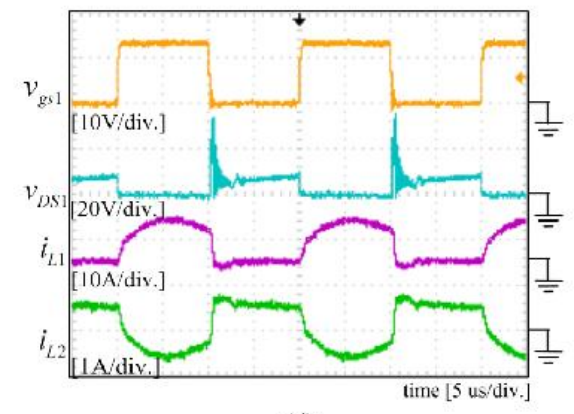

(d)

Fig. 3: Equivalent circuits of the flyback converter (a) - (c) using non-cross-coupled LCD snubber circuits during one switching cycle in CCM operation. The key waveforms (d) of flyback converter using LCD snubber circuits.

Meanwhile, Fig. 2(d) presents some experimental waveforms of the converter in CCM. When the switch $M_{1}$ is turned on and $M_{2}$ is turned off, the battery voltage $V_{B}$ is applied, and the current starts to flow through the primary side formed by $V_{B}, L_{l k g}, L_{1}$ and $M_{1}$. The energy is stored in the leakage inductance, $E_{L_{l k g}}=\frac{1}{2} L_{l k g} I^{2}$. The snubber diode $D_{s n 1}$ is reverse biased. The current $i_{L_{1}}$ is gradually increasing and circulating in the loop until the switch $M_{1}$ is turned off. Meanwhile, the voltage across the secondary transformer, $V_{L 2}$, is sufficiently large to forward bias the snubber diode $D_{s n 2}$ with $V_{L 2}=-n V_{B}$. The current $i_{L_{2}}$ is decreasing in the direction defined of $i_{L 2}$ as shown in Fig. 2(d) and circulating in the loop on the secondary side. When the switch $M_{1}$ is turned off and $M_{2}$ is remained off, the primary current $i_{L 1}$ flows 
to the RCD snubber and the transformer is reset. The energy transferred to $C_{s n 1}$ will be dissipating in the circuit through the snubber resistor $R_{s n 1}$. The peak MOSFET voltage is clamped to $V_{B}+V_{c s n 1} \geq V_{B}+\frac{V_{\text {out }}}{n}$. It can be seen that the converter is now operating effectively as a forward converter with $R_{s n 2}$ being the undesirable "main load" instead of $R_{L}$. Hence there is little actual power transferring to the designated load $R_{L}$.

For efficiency-sensitive applications, the non-dissipative snubber such as the LCD snubber is used. In addition to controlling the turn-off slew rate and clamping the voltage on the power transistor, this type of snubber can recycle the energy back to the source. Two LCD snubbers have been implemented for both sides of the transformer of the bidirectional flyback converter as shown in Fig. 1(b). The equivalent circuits are depicted in Figs. 3(a) to (c). Fig. 3(d) shows the corresponding waveforms of the converter in CCM. When the switch $M_{1}$ is closed, the current starts to flow through $L_{l k g}, L_{1}$ and $M_{1}$. The primary current $i_{L 1}$ rises. The energy is stored in the leakage inductance $E_{L_{l k g}}$. Meanwhile, the snubber capacitor $C_{s n 1}$ transfers its stored energy to $L_{s n 1}$. In the meantime, the voltage $V_{L 2}$ forces the snubber diode in $D_{4}$ to turned on as $V_{L 2}-V_{c s n 2}>V_{D}$, where $V_{D}$ is forward voltage drop of the diode $D_{4}$. The secondary inductor current $i_{L 2}$ is decreasing in the direction defined of $i_{L 2}$. A circulation current loop is formed by $L_{2}, C_{s n 2}$ and $D_{4}$. When $M_{1}$ is turned off and $M_{2}$ is remained off, the snubber diode $D_{1}$ starts to conduct and magnetizing inductor current, $i_{L M}$ charges the snubber capacitor $C_{s n 1}$. The energy stored in $L_{s n 1}$ is sent back to the input $V_{B}$ through $D_{2}$ and $D_{1}$. The voltage across the snubber capacitor $V_{c s n 1}$ and $V_{D S_{1}}$ start to increase. The $V_{D S_{1}}$ is clamped by $V_{B}+V_{s n 1}$. The current $i_{L 2}$ is start to decrease. In this condition, the snubber diode $D_{3}$ is forward biased while $D_{4}$ is reverse biased due to the blocking voltage $V_{L 2}+V_{c s n 2}$. The effect of circulating current will induce extra losses in the power switches and snubbers itself. Furthermore, it will cause the additional stress to the power devices as the high voltage spike occurs across the switch $V_{D S_{1}}$. As a result, it will degrade the efficiency. This is proven in Fig. 10 in Section VI of its poor conversion efficiency. To overcome this drawback, the proposed converter topology is introduced as depicted in Fig. 1(c). The cross-coupled LCD snubber is an improved version of the non-cross-coupled LCD snubber and will have better efficiency. The current circulation in the primary path will be minimized by transferring the leakage energy to the secondary side and directly to the output and vice versa.

\section{Operating Principles and Design Analysis of the PRoposed ConVERTER}

\section{A. Mode of Operation in CCM}

In CCM mode of operation, there are six operating intervals in one complete switching cycle. The proposed topology is simulated in LTSpice to validate the operation principle. Due to the identical and symmetrical operation for bidiretional power flow in this converter, only the power from the left to the right as shown in Fig. 1(c) is explained as follows. Fig. 4 shows the key waveforms of the proposed topology with the time intervals. Fig. 5 shows the equivalent circuit and current loops for each interval. To simplify the analysis without losing the key switching waveforms, the leakage inductance is lumped and modeled as $L_{l k g 1}$ which is in series with $L_{1}$ and $L_{l k g 2}$ which is in series with $L_{2}$.

1) Interval $I\left[t_{0}-t_{1}\right]$ : During this time interval, the main power switch $M_{1}$ is turned on, $M_{2}$ is turned off, and all diodes are turned on. The equivalent circuit is shown in Fig. 5(a). The magnetizing current $i_{L m_{1}}$ of the main transformer, which is formed by $L_{1}$ and $L_{2}$, starts to flow through the switching device $M_{1}$. The rate of change of $i_{L_{1}}$ can be expressed as

$$
\frac{d i_{L_{1}}}{d t}=\frac{V_{B}+n_{a} V_{H V}}{L_{l k g 1}}
$$

where $n_{a}=N_{a 2} / N_{a 1}$ is turns ratio of the main transformer. The snubber capacitor $C_{s n 1}$ and $L_{3}$ of the secondary transformer, form a resonant circuit. The resonant frequency is defined as

$$
\omega=\frac{1}{\sqrt{L_{3} C_{s n 1}}} .
$$

At the same time, a small magnetizing current $i_{L m_{4}}$ of the secondary transformer, which is formed by $L_{3}$ and $L_{4}$, flows in the current loop $L_{4}, C_{s n 2}$ and $D_{4}$. Note that this current is to reset the secondary transformer instead of the circulation current in the non-cross-coupled case in Fig. 3(a). The energy stored in $C_{s n 1}$ is transferred to the inductor $L_{3}$ until the current flows through this resonant circuit reaches zero at $t=t_{1}$.

2) Interval II $\left[t_{1}-t_{2}\right]$ : During this time interval, the main power switch $M_{1}$ is turned on and $M_{2}$ is remained off, and all diodes are in reversed biased as shown in Fig. 5(b). The resonant operation is ended in this mode. Only the magnetizing current $i_{L m_{1}}$, is flowing through the circuit. The primary inductor current $i_{L 1}$ increases linearly. This converter operates as a conventional type of a flyback converter. The voltage across the snubber capacitor $V_{c s n 1}$ $=-V_{B}$. When the main switch $M_{1}$ is turned off, this operational mode ends at $t=t_{2}$.

3) Interval III $\left[t_{2}-t_{3}\right]$ : During this time interval, the main power switches $M_{1}, M_{2}$ and diode $D_{2}$ are open, and diodes $D_{1}, D_{3}$ and $D_{4}$ are in forward biased, as shown in Fig. 5(c). The magnetizing inductance current $i_{L m_{1}}$ charges snubber capacitor $C_{s n 1}$ and parasitic capacitor $C_{D S}$ of $M_{1}$. The voltage across the switch $V_{D S 1}$ has raised sharply. The peak MOSFET voltage is clamped to $V_{B}+V_{c s n 1}$. The diodes $D_{3}$ and $D_{4}$ provide a path for energy to be transferred to the output via main transformer $N_{a 1}: N_{a 2}$. The operational mode ends when the primary inductor current $i_{L_{1}}$ reaches zero. The rate of change of $i_{L 1}$ during this interval can be written as

$$
\frac{d i_{L_{1}}}{d t}=-\left[\frac{V_{D S 1}+V_{c s n 1}}{L_{l k g 1}}+\frac{V_{D S 1}+V_{H V}}{L_{l k g 2}}\right] .
$$

4) Interval IV $\left[t_{3}-t_{4}\right]$ : During this time interval, the main power switches $M_{1}$ and $M_{2}$ are remained off, all diodes are in forward biased, as shown in Fig. 5(d). The oscillation happen caused by the resonant phenomena between the 


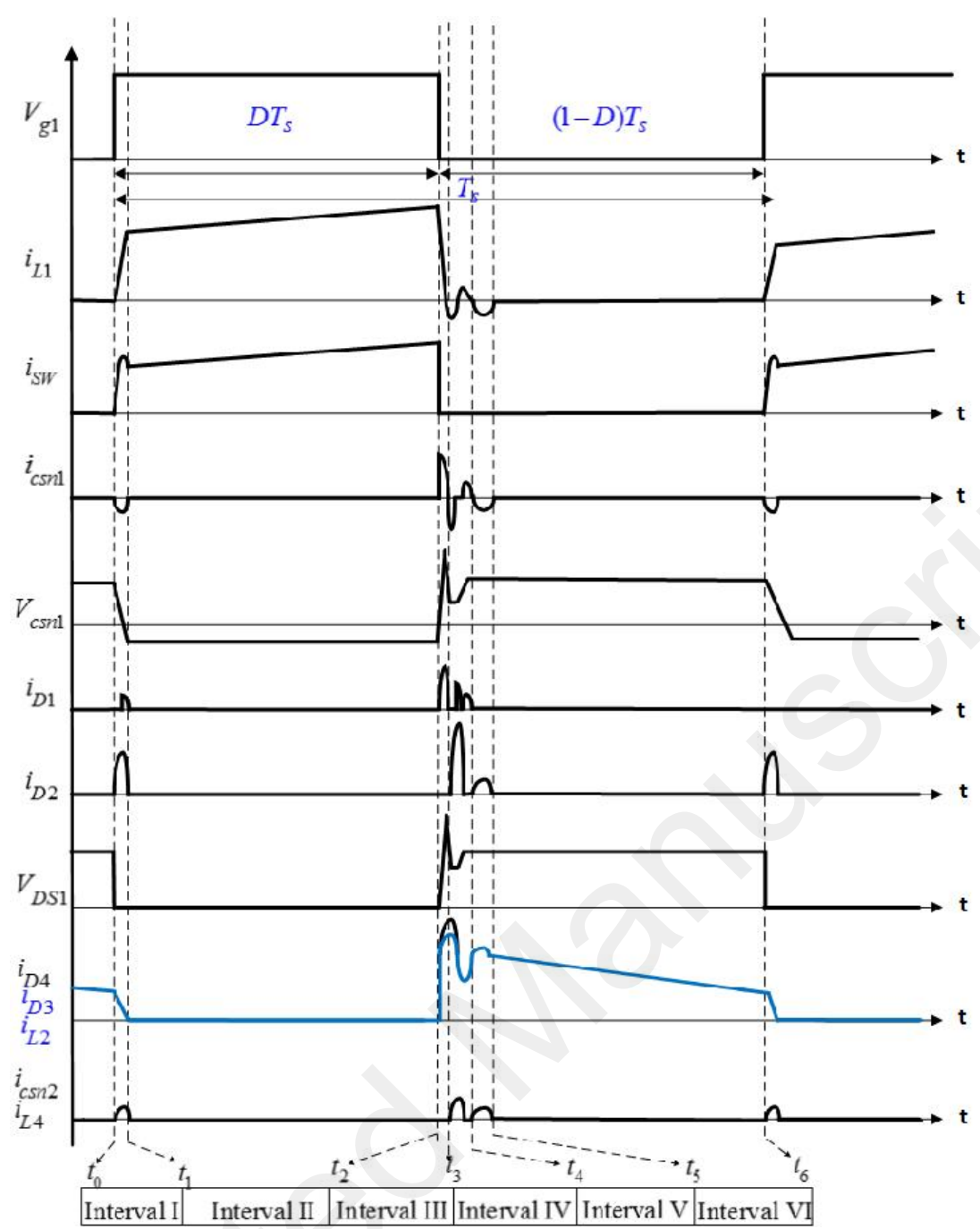

Fig. 4: Key waveforms of the proposed converter operating in CCM.

$L_{l k g}, C_{D S}$ and $C_{s n 1}$. In the meantime, the inductor current $i_{L_{3}}$ of the secondary transformer flows back to the input through $D_{1}$ and $D_{2}$. Hence, energy stored in the leakage inductance is fully transferred; $E_{l k g 1}=E_{c s n 1}$. Thus, the secondary transformer is reset. $D_{3}$ and $D_{4}$ conducting the current to the output.

5) Interval V $\left[t_{4}-t_{5}\right]$ : During this time interval, the main power switches $M_{1}$ and $M_{2}$ are remained off, diodes $D_{2}, D_{3}$ and $D_{4}$ continue conduction, and diode $D_{1}$ is reversed biased, as shown in Fig. 5(e). In this interval, the blocking voltage $V_{L 1}+V_{c s n 1}$ forces the snubber diode $D_{1}$ to be reverse biased. This mode ends when the inductor current $i_{L_{4}}$ reduces to zero.

6) Interval VI $\left[t_{5}-t_{6}\right]$ : During this time interval, the main power switches $M_{1}$ and $M_{2}$ remains in the non-conducting state, diodes $D_{1}$ and $D_{2}$ are turned off, and diodes $D_{3}$ and $D_{4}$ are forward biased, as shown in Fig. 5(f). $D_{3}$ and $D_{4}$ are conducting with inductor current $i_{L 2}$ of the main transformer flows to the output and decrease gradually. The converter operates as a conventional flyback converter. During this interval, $i_{L_{2}}$ decreases with a slope of

$$
\frac{d i_{L 2}}{d t}=-\left[\frac{V_{H V}}{L_{l k g 2}+L_{m 2}}\right] .
$$

This mode ends when the main switch $M_{1}$ is turned on again at $t=t_{6}$.

\section{B. Mode of Operation in DCM}

Compare to CCM, in DCM mode the magnetizing inductor has no energy at the beginning and at the end of the switching period. Fig. 6 shows the key waveforms of the proposed topology with the time intervals. For this operational circuit in DCM mode, there are six operating intervals in one complete switching cycle. The modes of operation are slightly similar with CCM, only intervals II, III, and VI are discussed;

1) Interval II $\left[t_{1}-t_{2}\right]$ : During this time interval, the main power switch $M_{1}$ is turned on, all diodes are reverse biased. The inductor current $i_{L 1}$ of the main transformer starts to flow through the switching device. The current $i_{L 1}$ increases linearly. $C_{s n 1}$ and $L_{3}$ continue the first resonant path from 


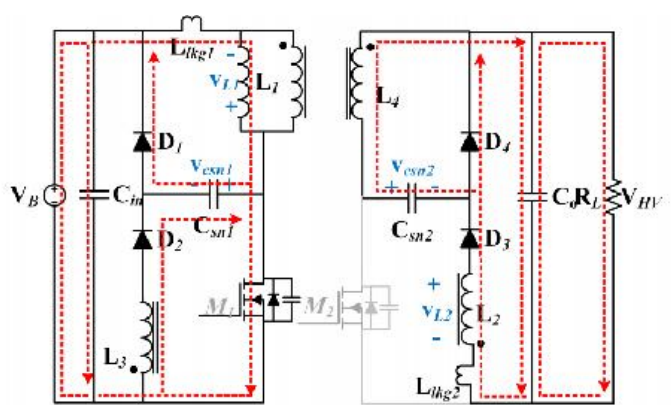

(a)

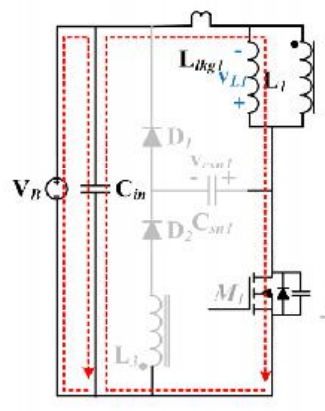

(b)

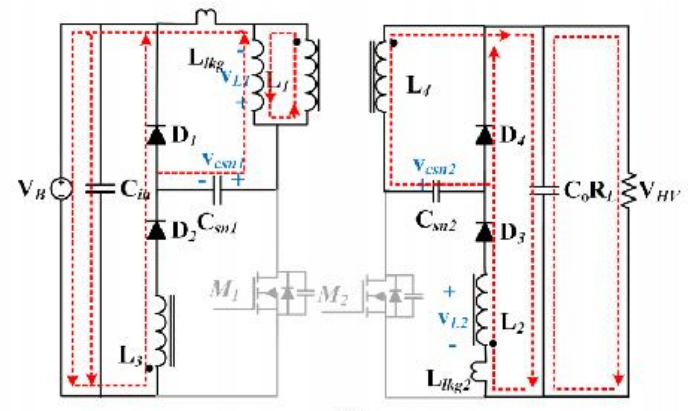

(d)

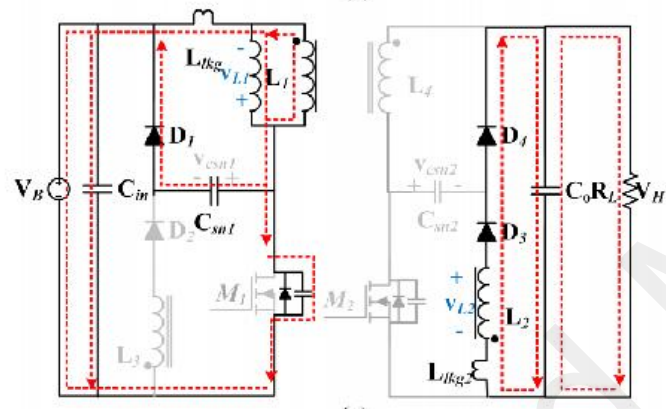

(c)

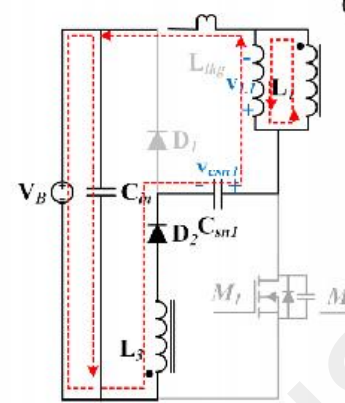

(e)
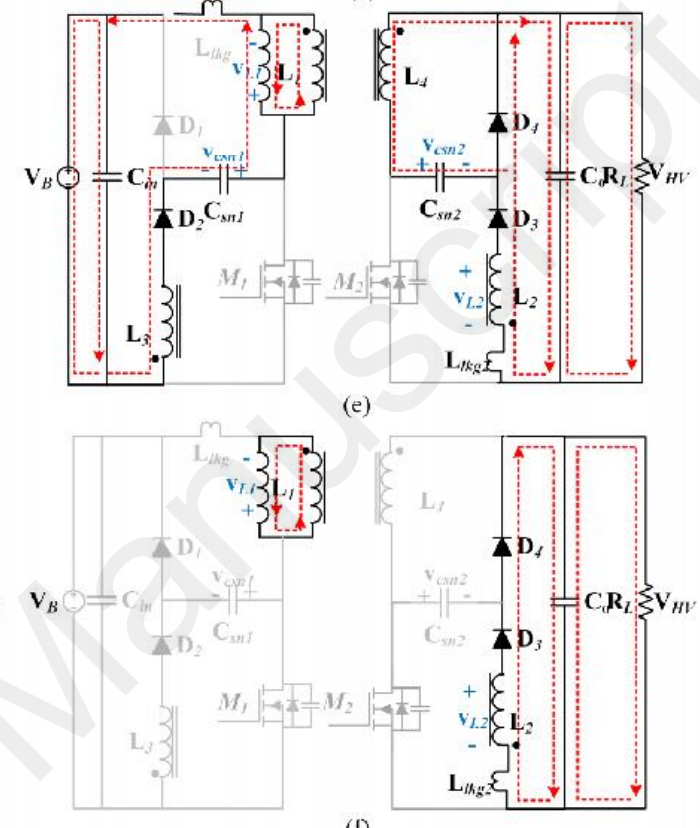

(I)

Fig. 5: Equivalent circuits of the proposed dc-dc converter during one switching cycle in CCM operation: (a) Interval I, (b) Interval II, (c) Interval III, (d) Interval IV, (e) Interval V, (f) Interval VI.

the previous interval. This mode ends when the current in $M_{1}, i_{S W_{1}}$ sharply decreases to zero at $t=t_{2}$.

2) Interval III $\left[t_{2}-t_{3}\right]$ : During this time interval, the main power switches $M_{1}$ and $M_{2}$ remain in the non-conducting state. The inductor current $i_{L 1}$ decreases to zero before the start of the next switching cycle at $t=t_{6}$. The energy stored in inductor $L_{1}$ starts to discharge into snubber capacitor $C_{s n 1}$ and transferred to the output $V_{\text {out }}$. This mode ends when the current in $L_{1}$ and $D_{1}$ reaches zero at $t=t_{3}$.

3) Interval VI $\left[t_{5}-t_{6}\right]$ : During this time interval, all the switching devices are turned off. It enters the final mode. Small ripple occurred in this mode in $V_{D S}$ by considering the appearance of the parasitic capacitor $C_{s s}$ in $M_{1}$. This mode ends when the main switch $M_{1}$ is turned on again at $t=$ $t_{6}$.

\section{Steady State Analysis}

In this section, a steady state analysis of the effect of leakage inductance on the voltage conversion is carried out. Assuming power is flowing from $V_{B}$ to $V_{H V}$, the voltages across the inductors $L_{1}$ and $L_{2}$ can be written as

$$
\begin{gathered}
V_{L 1}=V_{B} \frac{L_{m 1}}{L_{m 1}+L_{l k g 1}}\left(D T_{s}\right) \\
\mathrm{V}_{L 2}=-\frac{V_{H V}}{n_{a}}(1-D) T_{s} .
\end{gathered}
$$

where $D$ is the duty cycle. Based on the volt-second balance on the coupled inductor, the voltage conversion ratio of the proposed converter is given by

$$
M=\frac{V_{H V}}{V_{B}}=\frac{n_{a} D}{1-D} \cdot \frac{L_{m 1}}{L_{m 1}+L_{l k g 1}} .
$$

In an ideal condition where the windings are perfectly coupled, namely, $L_{l k g 1}=0$, the voltage conversion ratio is simplified to

$$
M=\frac{V_{H V}}{V_{B}}=\frac{n_{a} D}{(1-D)}
$$

where $n_{a}=N_{a 2} / N_{a 1}$ is the turns ratio of the main transformer. Fig. 7 illustrates the detailed plot of different voltage gains 


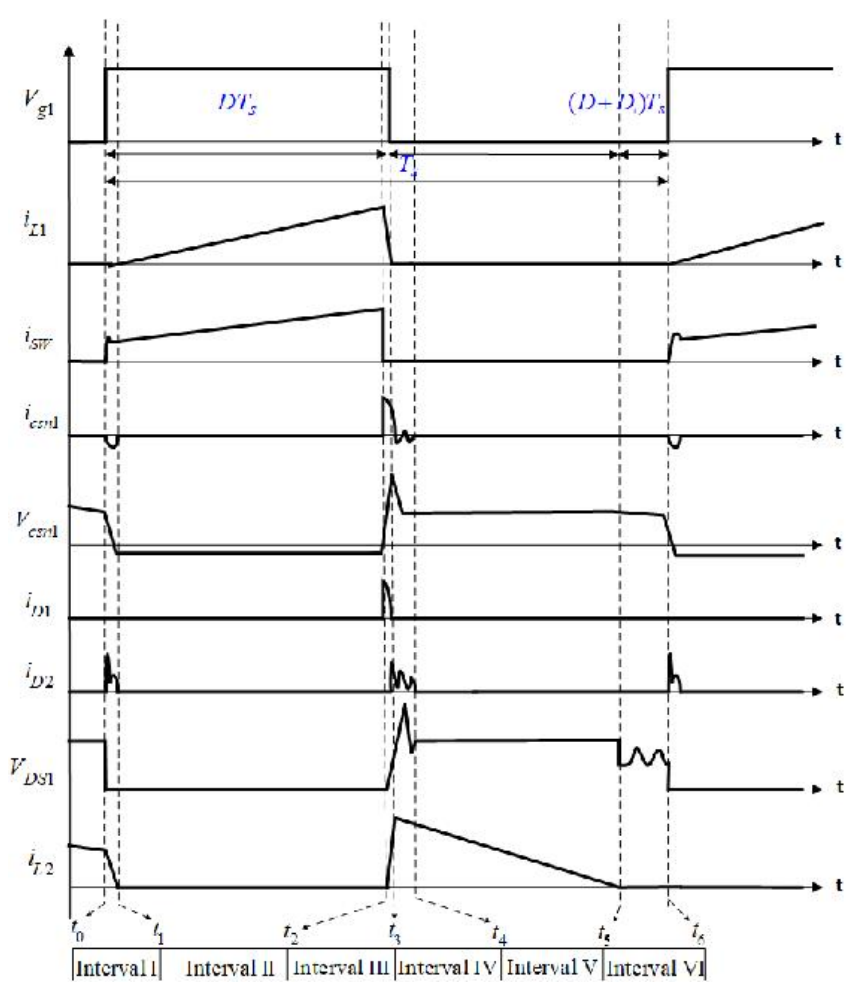

Fig. 6: Key waveforms of the proposed converter operating in DCM.

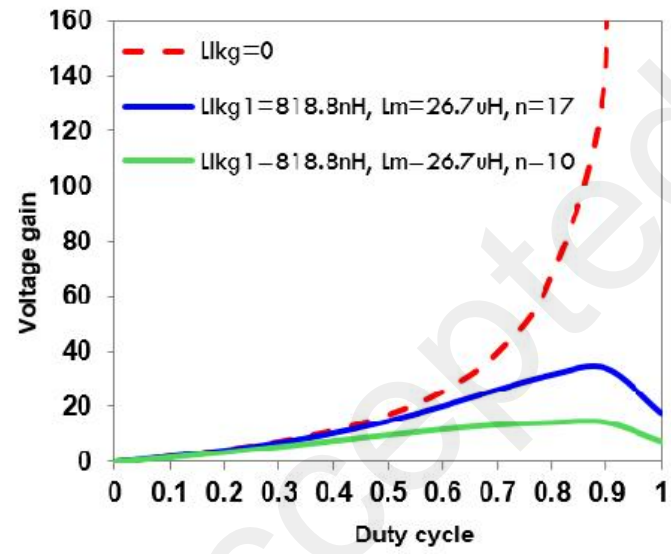

Fig. 7: Voltage gain versus duty cycle with and without leakage inductance in CCM step-up mode.

related to turns ratio and duty cycles with the absence and presence of leakage inductance. As shown in Fig. 7, for duty cycle $\leq 0.5$, the leakage inductance has little effect on the voltage conversion ratio $M$.

\section{Design of Snubber Capacitors}

In the proposed converter, high step-up voltage conversion requires the snubber circuit to be able to minimize and limit the additional voltage stress on the power transistors to a lower value. To reduce the voltage stress, high value of snubber capacitance is generally preferred. However, increasing the snubber capacitance value will increase the inductor currents.
TABLE I: Component Parameters

\begin{tabular}{cc}
\hline \hline Parameters & Values \\
\hline Battery Voltage, $V_{B}$ & $12 \mathrm{~V}$ \\
\hline High Voltage, $V_{H V}$ & $180 \mathrm{~V}$ \\
\hline Duty cycle, $D$ & 0.5 \\
\hline Switching frequency, $f_{s w}$ & $50 \mathrm{kHz}$ \\
\hline Maximum Output Power, $P_{\text {out }}$ & $50 \mathrm{~W}$ \\
\hline$C_{s n 1}$ and $C_{s n 2}$ & $22 \mathrm{nF}$ \\
\hline$C_{O}$ & $220 \mathrm{uF} / 450 \mathrm{~V}$ \\
\hline$M_{1}, M_{2}$ & $\mathrm{IRFP} 4332 \mathrm{PbF}$ \\
\hline Transformer (turns ratio for NCC) & $1: 17$ \\
\hline Transformer, $N_{a}$ (turns ratio for CC) & $1: 17$ \\
\hline Transformer, $N_{b}$ (turns ratio for CC) & $17: 1$ \\
\hline$D_{1}, D_{2}, D_{3}, D_{4}$ & $\mathrm{UG} 4 \mathrm{D}$ \\
\hline \hline
\end{tabular}

Also, the circulating currents may induce additional conduction losses through the switching device. Because of this reason, the optimum value of snubber capacitance is critical to minimize the energy losses. During turn on, the energy stored in the primary leakage inductance $L_{l k g 1}$ and snubber capacitor $C_{s n 1}$ are

$$
\begin{gathered}
E_{l k g 1}=\frac{1}{2} L_{l k g 1}\left[\left(i_{l k g_{1}, \max }\right)^{2}-\left(i_{l k g_{1}, \min }\right)^{2}\right] \\
E_{c s n 1}=\frac{1}{2} C_{s n 1}\left[\left(V_{c s n 1, \max }\right)^{2}+\left(V_{c s n 1, \min }\right)^{2}\right] .
\end{gathered}
$$

If the energy stored is fully transferred during turn off, it will obtained the following equation is obtained;

$$
E_{l k g 1}=E_{c s n 1} \text {. }
$$

The snubber design starts with the selection of maximum voltage spike on the main switch. Then by considering the effect of leakage inductances on the primary side, namely, combining (8), (9) and (10), the value of snubber capacitors $C_{s n 1}$ can be expressed as

$$
C_{s n 1}=\frac{L_{l k g 1}\left[i_{l k g_{1}, \max ^{2}}{ }^{2} i_{l k g_{1}, \min }{ }^{2}\right]}{\left[V_{c s n 1, \max ^{2}}+V_{c s n 1, \min }{ }^{2}\right]}
$$

where $i_{l k g_{1}, \max }$ and $i_{l k g_{1}, \text { min }}$ are the maximum and minimum leakage inductance currents respectively. While, $V_{c s n 1, \max }$ and $V_{c s n 1, \min }$ is the maximum and minimum voltage across snubber capacitor $C_{s n 1}$.

\section{EXPERIMENTAL VERIFICATION RESULTS OF THE PROPOSED CONVERTER}

To experimentally verify the operation and performance of the proposed converter, an $50 \mathrm{~W}$ laboratory hardware prototype is built and tested. Table I shows the design of the converter specifications and components. The snubber circuit is designed based on (11). The value of snubber capacitor is calculated based on the value of leakage inductance $L_{l k g 1}$. The assumption has been made for the value of the voltage spike $V_{Q 1}$. While the voltage spike is reduced, the high losses are appeared because of MOSFET turned off delay.

During step-up mode, Fig. 8(a) demonstrates the waveforms of the gate driving signal $V_{g s 1}$; the voltage stress across the switch $V_{D S 1}$; and the voltage across the load $V_{\text {out }}$. Meanwhile, in Fig. 8(b) it shows that current circulation for $i_{L 1}$ and $i_{L 2}$ 
TABLE II: Comparison of the proposed cross-coupled converter (CC), non-cross-coupled (NCC), the converter in [32], [33], and [34].

\begin{tabular}{|c|c|c|c|c|c|}
\hline Converter & Proposed CC & $\mathrm{NCC}$ & [32] & [33] & {$[34]$} \\
\hline Number of switches & 2 & 2 & 3 & 4 & 4 \\
\hline Number of diodes & 4 & 4 & 0 & 0 & 6 \\
\hline Gate driving & low-side & low-side & low-side \& high-side & low-side \& high-side & low-side \& high-side \\
\hline Number of gate drivers & 2 & 2 & $2-3$ & $3-4$ & $3-4$ \\
\hline Voltage-clamping switches & 2 out of 2 & 2 out of 2 & 3 out of 3 & 2 out of 4 & 4 out of 4 \\
\hline Number of capacitors & 4 & 4 & 1 & 3 & 4 \\
\hline Number of inductors & 0 & 2 & 0 & 2 & 1 \\
\hline Number of transformers & 2 & 1 & 1 & 1 & 2 \\
\hline Voltage gain & $\frac{n_{a} D}{(1-D)}$ & $\frac{n_{1}}{n_{2}} \frac{D}{(1-D)}$ & $\frac{n_{1}}{n_{2}} \frac{D}{(1-D)}$ & $\frac{2 n}{(1-D)}$ & $\frac{2 n D}{1-D}$ \\
\hline Voltage conversion ratio & $1: 15(12 \mathrm{~V}: 180 \mathrm{~V})$ & $1: 15(12 \mathrm{~V}: 180 \mathrm{~V})$ & $2: 1(24 \mathrm{~V}: 12 \mathrm{~V})$ & $1: 8(24 \mathrm{~V}: 200 \mathrm{~V})$ & $1: 8(48 \mathrm{~V}: 400 \mathrm{~V})$ \\
\hline Transformer turns ratio & $1: 17$ & $1: 17$ & $10: 30$ & $1.5: 1$ & $1: 3$ \\
\hline Power & $50 \mathrm{~W}$ & $50 \mathrm{~W}$ & $15 \mathrm{~W}-50 \mathrm{~W}$ & $200 \mathrm{~W}$ & $400 \mathrm{~W}$ \\
\hline Peak efficiency & $87 \%$ & $63 \%$ & $83 \%$ & $95.6 \%$ & $95.5 \%$ \\
\hline Switching & Hard-switched & Hard-switched & Soft-switched & Soft-switched & Soft-switched \\
\hline
\end{tabular}

TABLE III: Power Loss Distribution of the Proposed Converter in Step-Up Mode at Full Load (50 W).

\begin{tabular}{|c|c|c|c|}
\hline Components / Models & Parameters & Loss $(\mathrm{W})$ & $\%$ \\
\hline$M_{1}$ and $M_{2}$ (IRFP4332PBF) & $R_{d s, \text { on }}=29 \mathrm{~m} \Omega ; t_{o n}=85 \mathrm{~ns} ; t_{o f f}=85 \mathrm{~ns} ; C_{d s}=570 \mathrm{pF}$ & 4.67 & 9.34 \\
\hline$D_{1}, D_{2}, D_{3}, D_{4}(\mathrm{UG} 4 \mathrm{D})$ & $V_{d}: 0.95 \mathrm{~V}$ & 0.90 & 1.80 \\
\hline$C_{s n 1}$ and $C_{s n 2}(22 \mathrm{nF})$ & $R_{c}=0.2 \mathrm{~m} \Omega$ & 0.00 & 0.00 \\
\hline$C_{i n}$ and $C_{O}(220 \mathrm{uF} / 450 \mathrm{~V})$ & $R_{c}=0.2 \Omega$ & 0.03 & 0.06 \\
\hline Primary Transformer, $N_{a 1}: N_{a 2}$ (3C90) & $A_{c}=0.76 \mathrm{~mm}^{2} ; l_{m}=0.72 \mathrm{~mm} ; R_{d c}=3.06 \mathrm{~m} \Omega$ & 0.60 & 1.20 \\
\hline Secondary Transformer, $N_{b 1}: N_{b 2}(3 \mathrm{C} 90)$ & $A_{c}=0.76 \mathrm{~mm}^{2} ; l_{m}=0.72 \mathrm{~mm} ; R_{d c}=0.84 \Omega$ & 0.02 & 0.04 \\
\hline & Total Loss & 6.22 & 12.44 \\
\hline
\end{tabular}

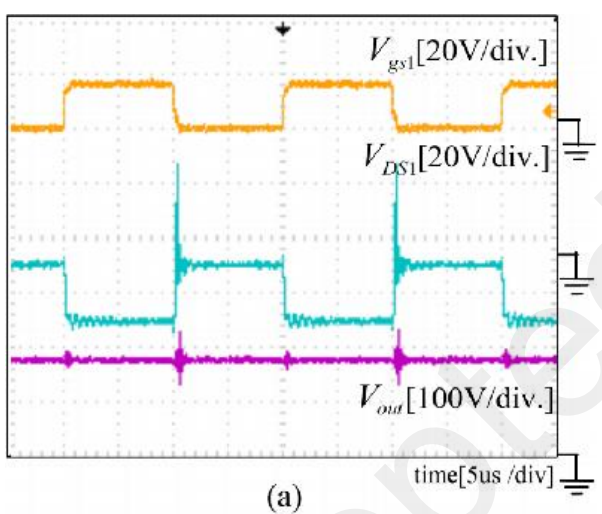

(a)

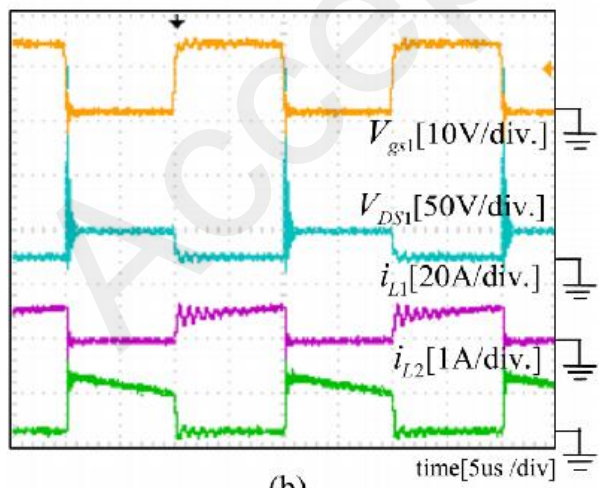

(b)

Fig. 8: Some experimental results in CCM with LCD crosscoupled snubber circuits in step-up mode. (a) $V_{g s 1}, V_{D S 1}$ and $V_{\text {out }}$. (b) $V_{g s 1}, V_{D S 1}, i_{L 1}$ and $i_{L 2}$.

on both sides of transformer reduce significantly compared to the previous topology with non-cross-coupled technique.
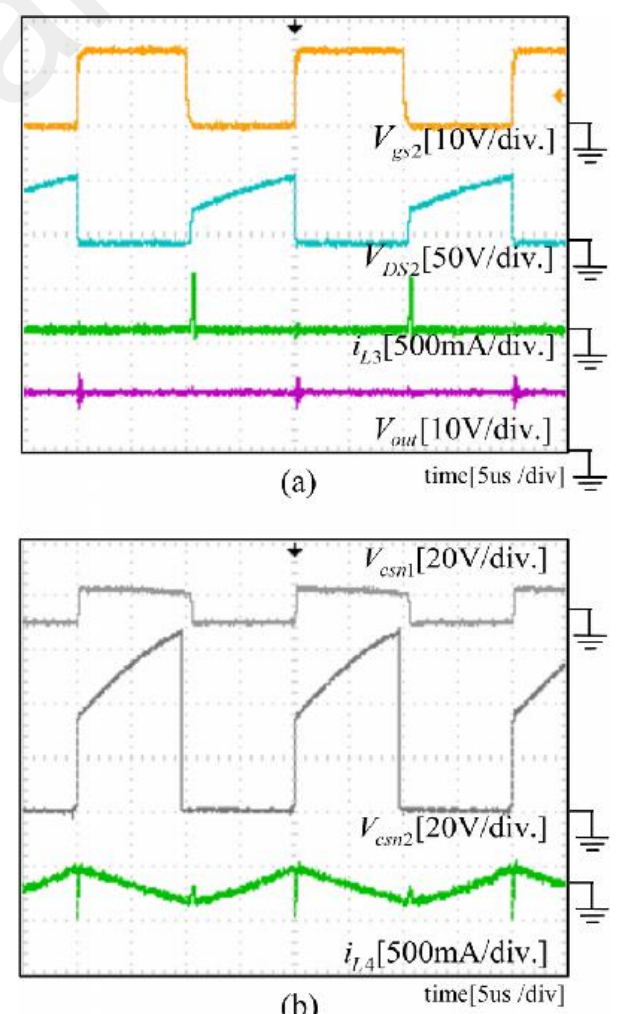

(b)

Fig. 9: Experimental results in CCM with LCD snubber circuits in step-down mode. (a) $V_{g s 2}, V_{D S 2}, i_{L 3}$ and $V_{\text {out }}$. (b) $V_{c s n 1}, V_{c s n 2}$, and $i_{L 4}$.

These figures validates the analysis in Section III.

Fig. 9(a) depicts the waveforms of $V_{g s 2}, V_{D S 2}$, low-side 


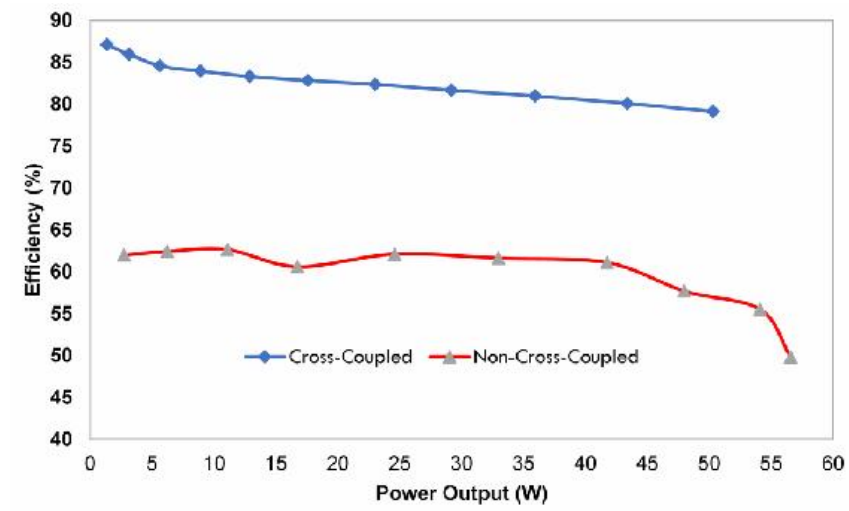

Fig. 10: Efficiency comparison between cross-coupled (CC) and non-cross-coupled (NCC) topology.

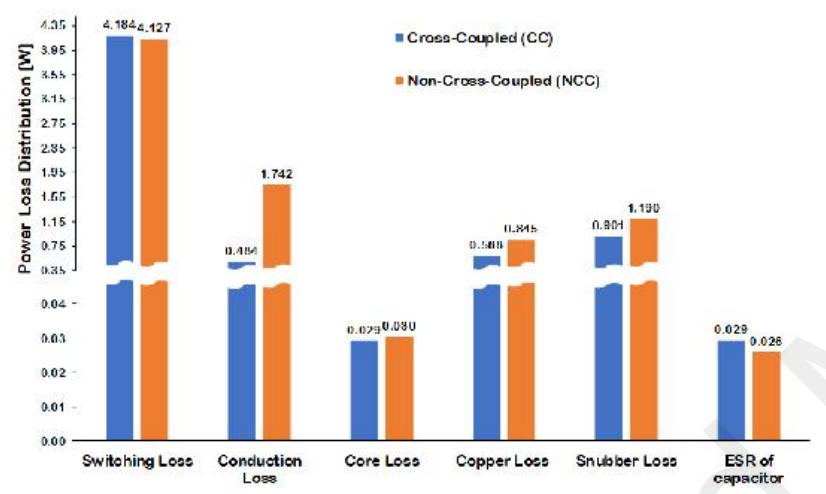

Fig. 11: Power loss comparison between cross-coupled (CC) and non-cross-coupled (NCC) topology.

current $i_{L 3}$, and $V_{\text {out }}$ during a few switching period of stepdown mode. According to the practical waveforms, it can be found that no circulating current in the loop of $i_{L 3}$. The energy stored in $L_{4}$ is transferred to the output through $L_{3}$. Meanwhile, Fig. 9(b) is the measurements of $V_{c s n 1}, V_{c s n 2}$ and the waveforms at the secondary winding current $i_{L 4}$. From $V_{c s n 2}$, it is shown that the energy stored in $L_{3}$ is recycled.

Table II compares the proposed converter among the other converters in terms of the number of active and passive components, voltage gain, efficiency, etc. The proposed converter can produce an output voltage with a voltage conversion ratio of $15: 1$, which is the highest gain amongst the other converters while maintaining reasonably high efficiency in hard-switched condition. With respect to the number of active components, only two power switches required for the proposed converter. Meanwhile, the converter in [33] and [34] entailed four active switches, and three active switches are applied in [32]. In addition, the number of gate drivers involved in the proposed topology is less than the other converters, where only low-side gate driving is used. Meanwhile, the expressions of voltage gain for conventional flyback converter, the proposed converter and the converter in [32] are the same. However, the current stress of the proposed converter is higher compared to the converters in [33] and [34], due to a comparatively larger voltage conversion ratio which requires a larger transformer turns ratio. Although the proposed converter has less component count, the efficiency is much lower than the converter in [33] and [34] due to hard-switched operation. However, the proposed converter has similar efficiency with the converter in [32]. However, the proposed cross-coupled has higher efficiency when compared to the non-cross-coupled topology.

Fig. 10 presents the measured conversion efficiencies of both the proposed (cross-coupled) and the non-cross-coupled case in step-up mode conditions. The peak efficiency of the proposed converter is nearly $90 \%$. Moreover, there is an efficiency improvement on average at $20 \%$ for the crosscoupled compared to the non-cross-coupled topology across the entire load range. The efficiency slightly decreases with the increase of the output power mainly due to the increase in conduction and switching losses. The switching loss of the proposed converter is higher due to its hard-switched operation.

Table III indicates the estimated power loss distribution of the proposed converter, where $V_{B}$ is $12 \mathrm{~V}$ and $V_{H V}$ is 180 $\mathrm{V}$. The selected parameter values of each components are based on the datasheets and the experimental tests. Fig. 11 shows the comparison of power loss distribution between cross-coupled and non-cross-coupled at full-load condition. The cross-coupled conduction loss is $0.484 \mathrm{~W}$, which is lower than non-cross-coupled conduction loss $1.742 \mathrm{~W}$. The calculation confirms the effect on minimizing the circulating currents through the circuit to decrease the conduction loss. In addition, the snubber losses of the cross-coupled converter and non-cross-coupled converter are $0.901 \mathrm{~W}$ and $1.190 \mathrm{~W}$, respectively. The non-cross-coupled technique converter uses the same parameters as that of the proposed cross-coupled converter except for the secondary winding. This confirms the analysis in Section II.

\section{CONCLUSION}

In this paper, the current circulation problem for flyback converters with RCD and non-cross-coupled (NCC) regenerative (i.e. LCD) snubbers is identified, explained and experimentally verified. To alleviate the current circulation problem, a bidirectional two-switch DC-DC flyback converter with two crossed-coupled LCD snubbers was then proposed. The primary flyback transformer is coupled to the snubber inductor on the secondary side, while the secondary transformer is coupled to the snubber inductor on the primary side. It offers advantages over the non-cross-coupled topology in terms of power loss and efficiency. In addition to reducing large voltage spikes during turned-off instants of the power transistors, the snubber circuits recycle leakage energy back to the source. Detailed analysis and operation principles were presented. Experimental results have verified the advantages of the proposed cross-coupled converter. Comparison with existing topologies in terms of component count, voltage gain and efficiency were provided. 


\section{REFERENCES}

[1] L.-S. Yang and T.-J. Liang, "Analysis and Implementation of a Nove Bidirectional DC-DC Converter," IEEE Trans. Ind. Electron., vol. 59, no. 1, pp. 422-434, 2012.

[2] L. Jiang, S. Member, C. C. Mi, S. Li, and M. Zhang, "A Novel SoftSwitching Bidirectional DC-DC Converter With Coupled Inductors," IEEE Trans. Ind. Appl., vol. 49, no. 6, pp. 2730-2740, 2013.

[3] G. Chen, Y. S. Lee, S. Y. R. Hui, D. Xu, and Y. Wang, "Actively clamped bidirectional flyback converter," IEEE Trans. Ind. Electron., vol. 47 no. 4, pp. 770-779, 2000.

[4] J. Yao, A. Abramovitz, and K. Ma Smedley, "Steep-Gain Bidirectional Converter with a Regenerative Snubber," IEEE Trans. Power Electron. vol. 30, no. 12, pp. 6845-6856, 2015

[5] K.-w. Ma and Y.-s. Lee, "An Integrated Flyback Converter for DC Unintemptible Power Supply," IEEE Trans. Power Electron., vol. 11 no. 2, pp. 318-327, 1996.

[6] A. Nasiri, Z. Nie, S. B. Bekiarov, and A. Emadi, "An On-Line UPS System with Power Factor Correction and Electric Isolation Using BIFRED Converter," IEEE Trans. Ind. Electron., vol. 1, no. 2, pp. 361366, 2003

[7] M. Arias, M. M. Hernando, D. G. Lamar, J. Sebastin, and A. Fernández, "Elimination of the transfer-time effects in line-interactive and passive standby UPSs by means of a small-size inverter," IEEE Trans. Power Electron., vol. 27, no. 3, pp. 1468-1478, 2012.

[8] L. Schuch, C. Rech, H. L. Hey, H. A. Gründling, H. Pinheiro, and J. R. Pinheiro, "Analysis and design of a new high-efficiency bidirectional integrated ZVT PWM converter for DC-bus and battery-bank interface," IEEE Trans. Ind. Appl., vol. 42, no. 5, pp. 1321-1332, 2006.

[9] S. Inoue and H. Akagi, "A bidirectional DC-DC converter for an energy storage system with galvanic isolation," IEEE Trans. Power Electron. vol. 22, no. 6, pp. 2299-2306, 2007.

[10] S. Y. Lee, A. G. Pfaelzer, and D. van Wyk, "Comparison of different designs of a 42-V/14-V DC/DC converter regarding losses and thermal aspects," IEEE Trans. Ind. Appl., vol. 43, no. 2, pp. 520-530, 2007.

[11] L. R. Chen, N. Y. Chu, C. S. Wang, and R. H. Liang, "Design of reflex-based bidirectional converter with the energy recovery function," IEEE Trans. Ind. Electron., vol. 55, no. 8, pp. 3022-3029, 2008

[12] S. Li, C. C. Mi, and M. Zhang, "A high-efficiency active batterybalancing circuit using multiwinding transformer," IEEE Trans. Ind. Appl., vol. 49, no. 1, pp. 198-207, 2013.

[13] F. Z. Peng, S. Member, F. Zhang, Z. Qian, and S. Member, "A MagneticLess DC - DC Converter for Dual-Voltage Automative Systems," IEEE Trans. Ind. Electron., vol. 39, no. 2, pp. 511-518, 2003.

[14] F. Z. Peng, M. Shen, and K. Holland, "Application of Z-Source Inverter for Traction Drive of Fuel Cell-Battery Hybrid Electric Vehicles," Power Electron. IEEE Trans., vol. 22, no. 3, pp. 1054-1061, 2007.

[15] T. Bhattacharya, V. Giri, K. Mathew, and L. Umanand, "Multiphase Bidirectional Flyback Converter Topology for Hybrid Electric Vehicles,' IEEE Trans. Ind. Electron., vol. 56, no. 1, pp. 78-84, 2009.

[16] Z. Amjadi and S. S. Williamson, "A Novel Control Technique for a Electric Vehicle Energy Storage System," IEEE Trans. Ind. Electron. vol. 57, no. 3, pp. 926-934, 2010.

[17] M. B. Camara, H. Gualous, F. Gustin, A. Berthon, and B. Dakyo, "DC/DC converter design for supercapacitor and battery power management in hybrid vehicle applicationspolynomial control strategy," IEEE Trans. Ind. Electron., vol. 57, no. 2, pp. 587-597, 2010.

[18] J. Cao and A. Emadi, "A new battery/ultracapacitor hybrid energy storage system for electric, hybrid, and plug-in hybrid electric vehicles," IEEE Trans. Power Electron., vol. 27, no. 1, pp. 122-132, 2012

[19] D. Velasco De La Fuente, C. L. Trujillo Rodríguez, G. Garcerá, E. Figueres, and R. Ortega Gonzalez, "Photovoltaic power system with battery backup with grid-connection and islanded operation capabilities,' IEEE Trans. Ind. Electron., vol. 60, no. 4, pp. 1571-1581, 2013.

[20] R. J. Wai and R. Y. Duan, "High-efficiency bidirectional converter for power sources with great voltage diversity," IEEE Trans. Power Electron., vol. 22, no. 5, pp. 1986-1996, 2007.

[21] R.-J. Wai, R.-Y. Duan, and K.-H. Jheng, "High-efficiency bidirectional dc-dc converter with high-voltage gain," IET Power Electron., vol. 5 , no. 2, p. 173,2012

[22] Y. P. Hsieh, J. F. Chen, L. S. Yang, C. Y. Wu, and W. S. Liu, "Highconversion-ratio bidirectional DC-DC converter with coupled inductor," IEEE Trans. Ind. Electron., vol. 61, no. 1, pp. 210-222, 2014.

[23] H. Ardi, A. Ajami, F. Kardan, and S. Nikpour, "Analysis and Implementation of a Non-Isolated Bidirectional DC-DC Converter with High Voltage Gain," IEEE Trans. Ind. Electron., vol. 0046, no. c, pp. 1-1, 2016.
[24] H. Wu, K. Sun, L. Chen, L. Zhu, and Y. Xing, "High Step-Up/StepDown Soft-Switching Bidirectional DC-DC Converter with CoupledInductor and Voltage Matching Control for Energy Storage Systems," IEEE Trans. Ind. Electron., vol. 63, no. 5, pp. 2892-2903, 2016.

[25] H. S.-h. Chung, S. Y. R. Hui, S. Member, and W.-h. Wang, "A ZeroCurrent-Switching PWM Flyback Converter with a Simple Auxiliary Switch," IEEE Trans. Power Electron., vol. 14, no. 2, pp. 329-342, 1999

[26] F. Zhang and Y. Yan, "Novel forward-flyback hybrid bidirectional DCDC converter," IEEE Trans. Ind. Electron., vol. 56, no. 5, pp. 1578-1584, 2009.

[27] G. Ma, W. Qu, G. Yu, Y. Liu, N. Liang, and W. Li, "A zero-voltageswitching bidirectional DC-DC converter with state analysis and softswitching-oriented design consideration," IEEE Trans. Ind. Electron. vol. 56, no. 6, pp. 2174-2184, 2009.

[28] B. R. Lin and C. L. Huang, "Asymmetrical pulse-width modulation bidirectional DC-DC converter," Int. Rev. Electr. Eng., vol. 6, no. 7, pp. 2846-2852, 2011

[29] T. Ninomiya, T. Tanaka, and H. Koosuke, "Analysis and optimization of a nondissipative LC turn-off snubber.pdf," IEEE Trans.Power Electron., vol. 3, no. No.2, 1988 .

[30] A. Abramovitz, C. S. Liao, and K. Smedley, "State-plane analysis of regenerative Snubber for Flyback converters," IEEE Trans. Power Electron., vol. 28 , no. 11 , pp. 5323-5332, 2013.

[31] J. H. Lee, T. J. Liang, and J. F. Chen, "Isolated coupled-inductorintegrated dc-dc converter with nondissipative snubber for solar energy applications," IEEE Trans. Ind. Electron., vol. 61, no. 7, pp. 3337-3348, 2014

[32] H. S.-h. Chung, S. Member, W.-l. Cheung, and K. S. Tang, "A ZCS Bidirectional Flyback DC/DC Converter," IEEE Trans.Power Electron., vol. 19, no. 6, pp. 1426-1434, 2004.

[33] T.-J. Liang and J.-H. Lee, "Novel High-Conversion-Ratio HighEfficiency Isolated Bidirectional DC-DC Converter," IEEE Trans. Ind. Electron., vol. 62, no. 7, pp. 4492-4503, 2015

[34] C.-L. Shen, H. Liou, T.-C. Liang, and H.-Z. Gong, "An Isolated Bidirectional Interleaved Converter With Minimum Active Switches and High Conversion Ratio," IEEE Trans. Ind. Electron., vol. 0046, no. c, pp. 1-1, 2017.

[35] N. M. Mukhtar and D. Dah-Chuan Lu, "A bidirectional flyback converter with cross-coupled non-dissipative snubber circuits," in INTELEC, Int. Telecommun. Energy Conf., pp. 476-481, 2017.

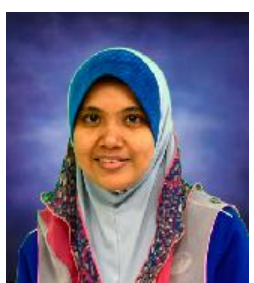

Nurhakimah Mohd Mukhtar (S'17) received the B.Eng in industrial electronics from the Universiti Malaysia Perlis, Malaysia and M.Eng in industrial electronics \& control from the University of Malaya, Malaysia in 2009 and 2011 respectively. She is currently working toward the Ph.D degree in electrical engineering at the School of Electrical and Information Engineering, The University of Sydney, Sydney, Australia.

She is also currently with the School of Electrical System Engineering, Universiti Malaysia Perlis, Malaysia. Her research interests include power electronics circuit, DC to DC converter and energy storage systems.

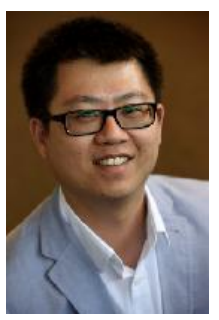

Dylan Dah-Chuan Lu (M'04-SM'09) received his B.E. and Ph.D. degrees in electronic and information engineering from the Hong Kong Polytechnic University, Hong Kong SAR, China, in 1999 and 2004 respectively.

In 2003, he joined Power ${ }^{\mathrm{L}}$ Lab Ltd. as a Senior Design Engineer where he was responsible for industrial switching power supply projects. He was a full-time faculty member with The University of Sydney from 2006 to 2016, where he now holds an Honorary position. Since July 2016, he has been an Associate Professor at the School of Electrical and Data Engineering, University of Technology Sydney, Australia. His current research interest includes efficient and reliable power conversion for renewable sources, energy storage systems, and microgrids. $\mathrm{He}$ is a Senior Member of IEEE and a Member of Engineers Australia.

He was a recipient of the Best Paper Award in the category of Emerging Power Electronic Technique at the IEEE PEDS 2015. He is presently serving as an Associate Editor of the IEEE Transactions on Circuits and Systems II: Express Briefs and a Subject Editor of the IET Renewable Power Generation. 